\title{
Late-Onset Familial Amyloid Polyneuropathy (FAP) Val30Met Without Family History
}

\author{
Thomas Rudolph; Martin Wilhelm Kurz; and Elisabeth Farbu
}

\begin{abstract}
Familial amyloid polyneuropathy (FAP) is rare and most commonly caused by the Val30Met mutation of the transthyretin (TTR) gene. Beside polyneuropathy, other complications due to amyloid deposits occur, but may vary in phenotype. The mutation tends to occur in endemic clusters. We describe a 65-year-old man from a non-endemic FAPVal30Met area who developed a progressive generalized painless axonal sensorimotor polyneuropathy with mild autonomic involvement and absent FAP symptoms in the family. Nerve biopsy showed amyloid deposits, staining with TTR-antibodies on immunohistochemistry.After DNA-sequencing of the TTR gene, the diagnosis of FAP Val30Met was made. Late-onset FAP Val30Met is a progressive and fatal disorder with varying penetrance, and may occur in non-endemic areas and cases without a family history.
\end{abstract}

Keywords: DNA-sequencing; Familial amyloid polyneuropathy; Nerve biopsy; TTR-gene; Val30Met mutation

Reprint Requests:

Dr. Thomas Rudolph

Department of Neurology

Stavanger University Hospital

Postboks 8100

4068 Stavanger, Norway

Telephone: +475 I 5 I 8636

Fax: +4751519916

Email: mokum99@online.no

Received: April 8, 2008

Revised: June 10, 2008

Accepted: June 18, 2008

doi: $10.3121 / \mathrm{cmr} .2008 .794$
$\mathrm{T}$ ransthyretin (TTR) derives mostly from the liver, acts as a transport protein for thyroxine and vitamin A, and plays an important role in the transport of thyroxine across the blood-brain and blood-choroid plexus-cerebrospinal fluid barriers. ${ }^{1}$ Familial amyloid polyneuropathy (FAP) is most commonly caused by mutated TTR, exchanging valine for methionine at position 30 (ATTR Val30Met). ${ }^{2}$ Overall prevalence is low, but endemic clusters occur in Sweden, Portugal and Japan, ${ }^{3-5}$ affecting approximately one per 1000 inhabitants. The disease is autosomal, dominantly inherited, and variable in penetrance. Clinically, a sensorimotor polyneuropathy with autonomic involvement is typical. Untreated the course is devastating, leading to multiple amyloidotic organ complications and most patients die of cardiac complications. Nerve biopsy may detect amyloid deposits and the diagnosis is confirmed by DNA sequencing of the TTR gene. ${ }^{6}$ Liver transplantation is accepted as treatment for the disease. ${ }^{7}$ We describe a patient with FAP Val30Met in a non-endemic FAP area underlining that this mutation should be considered in the elderly, even without a family history.

\section{Case Report}

A 65-year-old man with repaglinide-treated diabetes from the area of Duesseldorf, Germany, was admitted to the neurology department after having consulted three different neurologists within 3 years because of progressive numbness and weakness with symmetrical distribution in his feet 3 years earlier. He was given various diagnoses of polyneuropathy, including diabetic, idiopathic, and immune-mediated polyneuropathy. The sensation deteriorated 
Table 1. Nerve conduction findings.

\begin{tabular}{|c|c|c|c|c|}
\hline \multirow[b]{2}{*}{$\begin{array}{l}\text { Nerve and stimulation sites } \\
\text { (right side) }\end{array}$} & \multicolumn{2}{|c|}{ Response } & \multirow[b]{2}{*}{$\begin{array}{l}\text { Conduction velocity } \\
\qquad(\mathrm{m} / \mathrm{s})\end{array}$} & \multirow[b]{2}{*}{ F-latency (ms) } \\
\hline & $\begin{array}{l}\text { Latency } \\
\text { amplitude }\end{array}$ & $(\mathrm{ms})(\mathrm{mV})$ & & \\
\hline \multicolumn{5}{|l|}{ Ulnar motor } \\
\hline Wrist & 3,5 & 3,5 & & \\
\hline Below elbow & 9,5 & 2,8 & 42 & 41 \\
\hline \multicolumn{5}{|l|}{ Ulnar sensory } \\
\hline Wrist, digit 5 & NR & & & \\
\hline \multicolumn{5}{|l|}{ Tibial motor } \\
\hline Ankle & & & & \\
\hline Popliteal fossa & NR & & & \\
\hline \multicolumn{5}{|l|}{ Peroneal motor } \\
\hline Ankle & & & & \\
\hline Fibular head & NR & & & \\
\hline \multicolumn{5}{|l|}{ Sural sensory } \\
\hline Lower leg, ankle & NR & & & \\
\hline
\end{tabular}

NR, not recordable.

to the ankles and fingers. One year before admission he became unsteady while walking and noticed increasing weakness in both feet.

Examination showed hypalgesia and hypesthesia below the wrists in the hands, below the knees, and in both feet. Vibration and joint position was mildly reduced on the wrists and absent below the knees and ankles. He denied painful sensations. Motor strength was $4 / 5$ in the small hand muscles, $4 / 5$ in hip flexors, knee flexors, feet extensors, toe extensors and flexors and $3 / 5$ on dorsiflexion of the feet. There was moderate atrophy of both the small hand muscles and the intrinsic muscles of the feet. Deep tendon-reflexes were positive in the arms, but absent in the knees and ankles. The patient did not report signs of autonomic dysfunction. On clinical examination, no signs of autonomic involvement were evident.

Nerve conduction studies (table 1) and needle electromyographic recordings (spontaneous muscle activity and reduced amplitude of the compound muscle action potential in the first dorsal interosseous muscle in both hands and the tibialis anterior muscle in both legs) were compatible with an axonal sensorimotor polyneuropathy. Autonomic testing found absent heart rhythm variance, suggesting autonomic involvement. A nerve biopsy showed amyloid deposits, staining with TTR-antibodies on immunohistochemistry. A heterozygous Val30Met mutation was identified by DNA analysis. After intensive investigation, no other potential sites of amyloid were found. FAP symptoms were absent in the family. The mutation was not found in his daughter. Genetic testing was not performed in his parents. Finally, complete or partial liver transplantation between the patient and his healthy daughter was considered to treat the disorder. However, liver transplantation was not performed after a multidisciplinary discussion.

\section{Discussion}

FAP Val30Met should be considered in non-endemic areas, even without a family history. The disorder tends to occur in endemic clusters with affected parents. ${ }^{3,4}$ In contrast, $13 \%$ of the patients may have a negative family history. ${ }^{8}$ In our case of FAP Val30Met without a family history, we suspected a de novo mutation of the TTR gene. However, FAP Val30Met may vary in phenotype due to varying penetrance, and may even be asymptomatic due to parental germline mosaicism. 5,8,9 Thus, inherited mutation of the TTR gene from asymptomatic parents could not be ruled out completely in this case because genetic testing was not performed in the parents. The disease is autosomal dominant of inheritance and the majority of the patients, our patient as well, are heterozygous for the Val30Met mutation.

Polyneuropathy due to FAP Val30Met is extremely rare below the age of 20 years, and is not clinically relevant below 30.4 Our patient had a late onset of FAP at age 62, suggesting variance in age at onset, as previously described in different populations with the Val30Met TTR gene mutation carrying the same haplotype. ${ }^{4,10}$ That is probably because of the influence by modifying genetic loci and/or environmental factors. ${ }^{7}$

In line with previous findings, describing a distinctive type of late onset FAP Val30Met in Japan, severe painless generalized axonal sensorimotor polyneuropathy with mild autonomic involvement, not related to endemic foci, was typical. Initial cardiac involvement may be found in $5 \%$ to $23 \%$ of late onset FAP with different ethnic background. 3,11 Our patient did not show morphological echocardiographic abnormalities, but other cardiac measurements disclosing early signs of functional cardiac complications were not performed. ${ }^{12}$ Additionally, little relation to endemic foci, as in our case, probably reflects a widespread distribution of the disease. 3,13 
In conclusion, late onset FAP Val30Met should be considered in elderly patients, developing a progressive axonal sensorimotor polyneuropathy with autonomic involvement, even in non-endemic areas and cases without a family history.

\section{References}

1. Saraiva MJ. Cellular consequences of transthyretin deposition. Amyloid 2003;10(suppl 1):13-16.

2. Connors LH, Richardson AM, Théberge R, Costello CE. Tabulation of transthyretin (TTR) variants as of 1/1/2000. Amyloid 2000;7:54-69.

3. Koike H, Misu K, Ikeda S, Ando Y, Nakazato M, Ando E, Nakazato M, Ando E, Yamamoto M, Hattori N, Sobue G; Study Group for Hereditary Neuropathy in Japan. Type I (transthyretin Met30) familial amyloid polyneuropathy in Japan: early- vs. late-onset form. Arch Neurol 2002; 59:1771-1776.

4. Sousa A, Coelho T, Barros J, Sequeiros J. Genetic epidemiology of familial amyloidotic polyneuropathy (FAP)-type I in Póvoa do Varzim and Vila do Conde (north of Portugal). Am J Med Genet 1995;60:512-521.

5. Sousa A, Andersson R, Drugge U, Holmgren G, Sandgren O. Familial amyloidotic polyneuropathy in Sweden: geographical distribution, age of onset, and prevalence. Hum Hered 1993;43:288-294.

6. Soares ML, Coelho T, Sousa A, Batalov S, Conceição I, Sales-Lu's ML, Ritchie MD, Williams SM, Nievergelt CM, Schork NJ, Saraiva MJ, Buxbaum JN. Susceptibility and modifier genes in Portuguese transthyretin V30M amyloid polyneuropathy: complexity in a single-gene disease. Hum Mol Genet 2005; 14:543-553.

7. Suhr O. Impact of liver transplantation on familial amyloidotic polyneuropathy (FAP) patients' symptoms and complications. Amyloid 2003;10(suppl 1):77-83.

8. Coelho T, Sousa A, Lourenco E, Ramalheira J. A study of 159 Portuguese patients with familial amyloidotic polyneuropathy (FAP) whose parents were both unaffected. J Med Genet 1994;31:293-299.

9. Yazaki M, Yamashita T, Kincaid JC, Scott JR, Auger RG, Dyck PJ, Benson MD. Rapidly progressive amyloid polyneuropathy associated with a novel variant transthyretin serine 25 . Muscle Nerve 2002;25:244-250.

10. Almeida MR, Aoyama-Oishi N, Sakaki Y, Holmgren G, Ulf D, Ferlini A, Salvi F, Munar-Oués M, Benson MD, Skinner M, Costa PP, Saraiva MJ. Haplotype analysis of common transthyretin mutations. Hum Genet 1995;96:350-354.

11. Conceição I, De Carvalho M. Clinical variability in type I familial amyloid polyneuropathy (Val30Met): comparison between late- and early-onset cases in Portugal. Muscle Nerve 2007;35:116-118.

12. Lindqvist P, Olofsson BO, Backman C, Suhr O, Waldenström A. Pulsed tissue Doppler and strain imaging discloses early signs of infiltrative cardiac disease: a study on patients with familial amyloidotic polyneuropathy. Eur J Echocardiogr 2006; 7:22-30

13. Misu K, Hattori N, Nagamatsu M, Ikeda S, Ando Y, Nakazato M, Takei Y, Hanyu N, Usui Y, Tanaka F, Harada T, Inukai A, Hashizume Y, Sobue G. Late-onset familial amyloid polyneuropathy type I (transthyretin Met30-associated familial amyloid polyneuropathy) unrelated to endemic focus in Japan. Clinicopathological and genetic features. Brain 1999;10:1951-1962.
Author Affiliations

Thomas Rudolph

Department of Neurology

Stavanger University Hospital, Norway

Martin Wilhelm Kurz

Department of Neurology

Stavanger University Hospital, Norway and

Department of Neurology

University Hospital of Duesseldorf, Germany

Elisabeth Farbu

Department of Neurology

Stavanger University Hospital, Norway 